Supporting Information for

\title{
Temperature independent kinetic isotope effects as evidence for a Marcus-like model of hydride tunneling in phosphite dehydrogenase
}

Graeme W. Howe ${ }^{*, \dagger, t, \omega}$ and Wilfred van der Donk ${ }^{*, \dagger, \dagger, \S}$

${ }^{\dagger}$ Department of Chemistry, University of Illinois at Urbana-Champaign, 600 South Mathews Avenue, Urbana, Illinois 61801, United States

Carl R. Woese Institute for Genomic Biology, University of Illinois at Urbana-Champaign, 1206 West Gregory Drive, Urbana, Illinois 61801, United States

${ }^{\S}$ Howard Hughes Medical Institute, University of Illinois at Urbana-Champaign, 1206 West Gregory Drive, Urbana, Illinois 61801, United States

${ }^{\omega}$ Present address: Department of Chemistry, Queen's University, Kingston, ON, Canada, K7L $3 \mathrm{~N} 6$

*Correspondence to: vddonk@illinois.edu; graeme.howe@queensu.ca 
Table S1. ${ }^{\mathrm{D}} \boldsymbol{k}_{\text {cat }}$ values observed with 17X-PTDH at various temperatures ${ }^{\mathrm{a}}$

\begin{tabular}{|l|l|}
\hline $\begin{array}{l}\text { Temperature } \\
\left({ }^{\circ} \mathrm{C}\right)\end{array}$ & ${ }^{\mathrm{D}} \boldsymbol{k}_{\text {cat }}$ \\
\hline 5 & $2.30 \pm 0.05$ \\
\hline 10 & $2.30 \pm 0.07$ \\
\hline 15 & $2.28 \pm 0.04$ \\
\hline 20 & $2.30 \pm 0.05$ \\
\hline 25 & $2.26 \pm 0.04$ \\
\hline 30 & $2.25 \pm 0.04$ \\
\hline 35 & $2.26 \pm 0.04$ \\
\hline 40 & $2.17 \pm 0.07$ \\
\hline 45 & $2.22 \pm 0.05$ \\
\hline
\end{tabular}

${ }^{\mathrm{a}}$ All values obtained in $100 \mathrm{mM}$ MOPS, $\mathrm{pH} 7.25$. Values are the average of three replicates and associated errors are the standard deviation of those replicates.

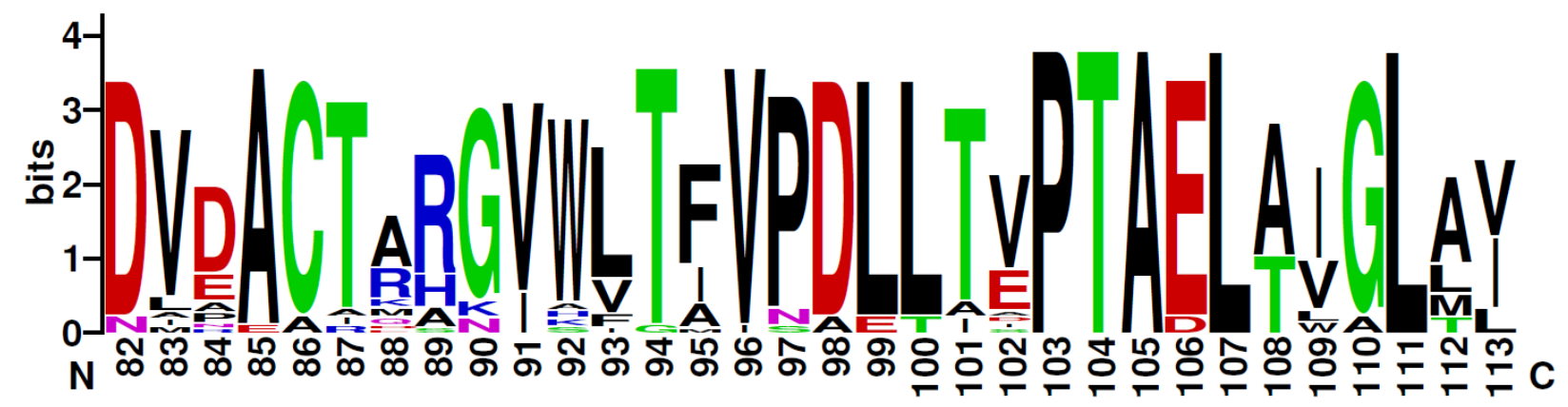

Figure S1. WebLogo of 409 aligned sequences of proteins with $>40 \%$ identity to PTDH from Pseudomonas putida. Numbering corresponds to the sequence of PTDH from P. stutzeri (UniProt accession code O69054). Thr104 (see text) is fully conserved. 

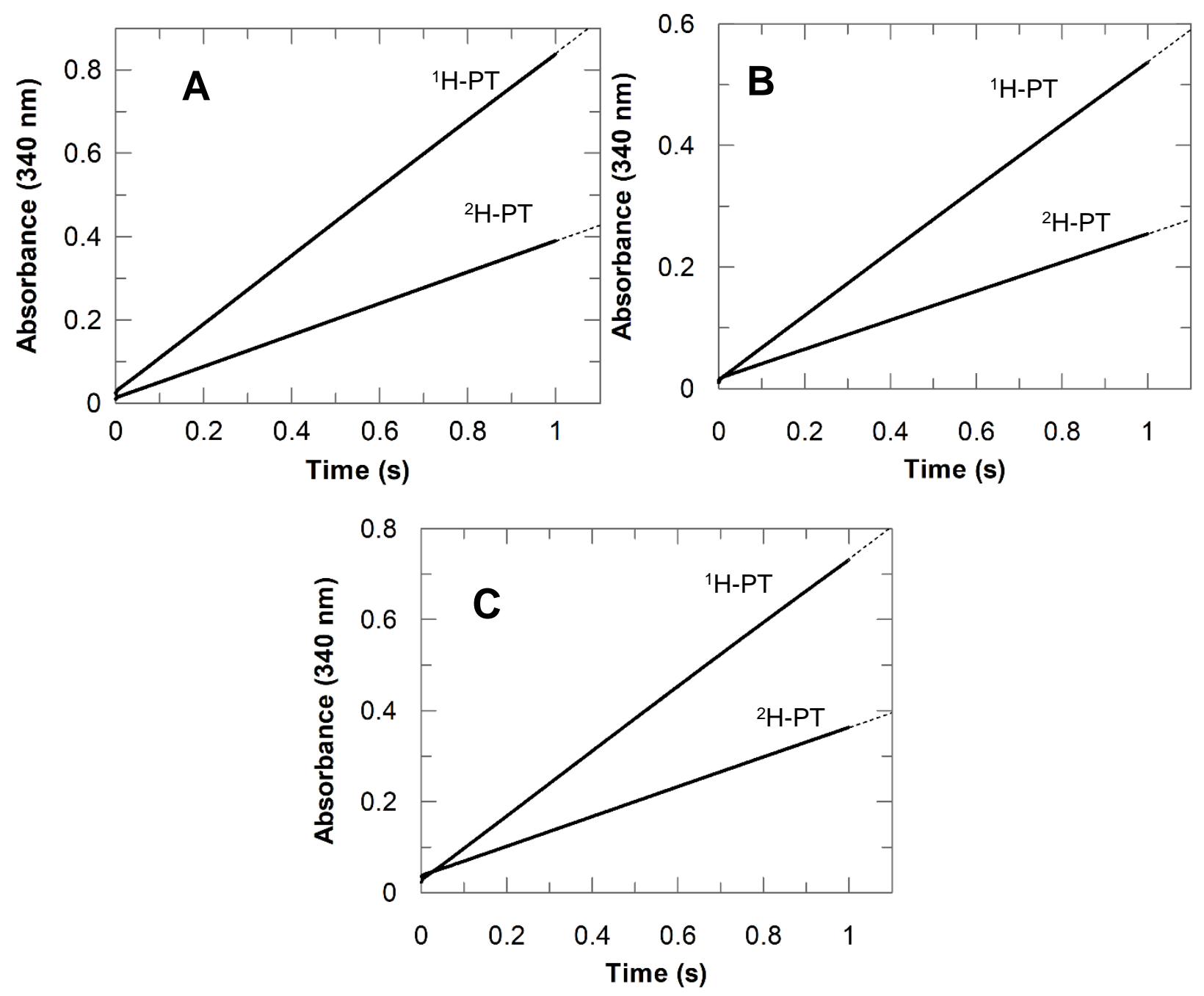

Figure S2. Pre-steady-state traces for (A) T104S-, (B) T104A-, and (C) T104G-17X-PTDH collected at $45^{\circ} \mathrm{C}$. Lines represent the average of five pre-steady-state traces obtained by mixing a solution of T104X-17X-PTDH (70 $\mu \mathrm{M}$ T104S-17X-PTDH in Panel A; $100 \mu \mathrm{M}$ T104A-17XPTDH in Panel B; $200 \mu \mathrm{M}$ T104G-17X-PTDH in Panel B;) with a solution of $10 \mathrm{mM}{ }^{1} \mathrm{H}-$ or ${ }^{2} \mathrm{H}-$ $\mathrm{PT}, 10 \mathrm{mM} \mathrm{NAD}^{+}$in $100 \mathrm{mM}$ MOPS, $\mathrm{pH}$ 7.25. Data is fit to the zeroth-order rate law. Absorbance values corresponding to a single turnover are 0.43 in Panel A, 0.62 in Panel B, and 1.24 in Panel C. 
Table S2. KIEs obtained with T104X-17X-PTDH by steady-state and pre-steady-state measurements at $45^{\circ} \mathrm{C} .{ }^{\text {a }}$

\begin{tabular}{|c|c|c|c|}
\hline Variant & ${ }^{\mathrm{D}} k_{\text {cat }}{ }^{\mathrm{b}}$ & ${ }^{\mathrm{D}}\left(k_{\text {cat }} / K_{\mathrm{m}, \mathrm{PT}}\right)^{\mathrm{b}}$ & ${ }^{\mathrm{D}} k_{\text {obs }}{ }^{\mathrm{c}}$ \\
\hline $\mathrm{T} 104 \mathrm{~S}$ & $2.16 \pm 0.05$ & $2.1 \pm 0.2$ & $2.15 \pm 0.02$ \\
\hline $\mathrm{T} 104 \mathrm{~A}$ & $2.03 \pm 0.07$ & $2.2 \pm 0.1$ & $2.20 \pm 0.02$ \\
\hline $\mathrm{T} 104 \mathrm{G}$ & $2.05 \pm 0.03$ & $2.2 \pm 0.1$ & $2.16 \pm 0.03$ \\
\hline
\end{tabular}

${ }^{\mathrm{a}}$ All data was collected using $100 \mathrm{mM}$ MOPS at $\mathrm{pH} 7.25 .{ }^{b}$ Values derived from Michaelis-Menten curves constructed from steady-state measurements obtained using saturating concentrations of $\mathrm{NAD}^{+}$and varied concentration of ${ }^{1} \mathrm{H}$ - or ${ }^{2} \mathrm{H}-\mathrm{PT}$. ${ }^{\mathrm{c}}$ Values derived from fits of pre-steady-state traces to the zeroth order rate law.

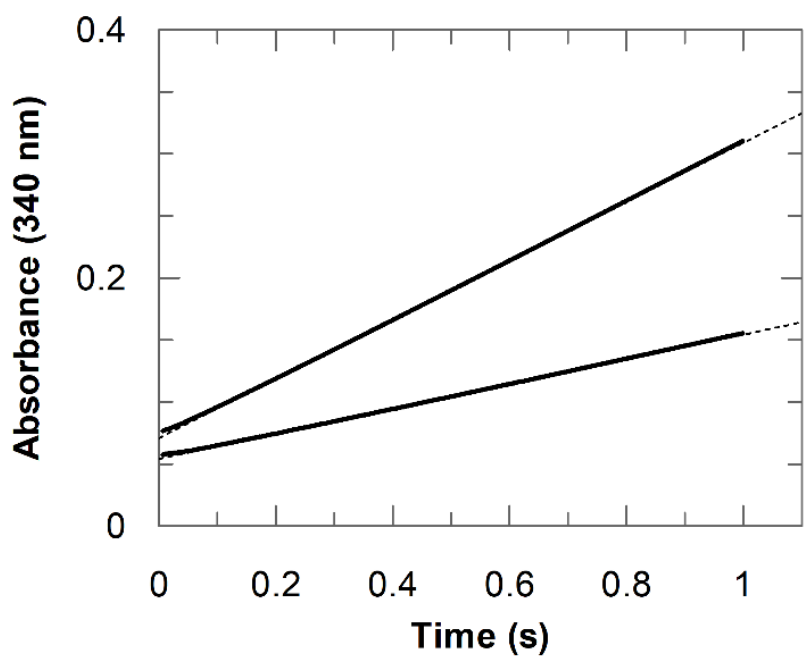

Figure S3. Pre-steady-state traces for T104S-17X-PTDH collected at $5{ }^{\circ} \mathrm{C}$. Lines represent the average of five pre-steady-state traces obtained by mixing a solution of T104S-17X-PTDH (400 $\mu \mathrm{M})$ with a solution of $10 \mathrm{mM}{ }^{1} \mathrm{H}-$ or ${ }^{2} \mathrm{H}-\mathrm{PT}, 10 \mathrm{mM} \mathrm{NAD}^{+}$in $100 \mathrm{mM}$ MOPS, pH 7.25. Data is fit to the zeroth-order rate law. 

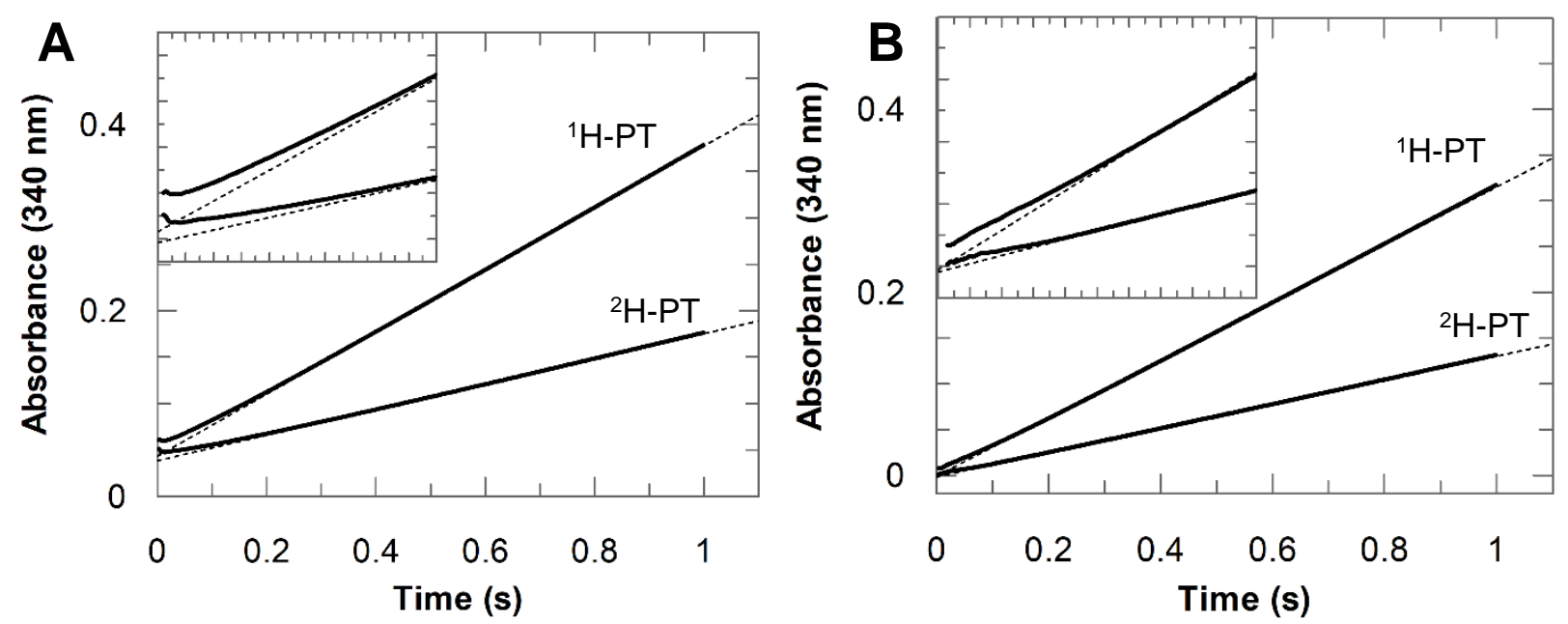

Figure S4. Averaged pre-steady-state traces for T104A-17X-PTDH at $5{ }^{\circ} \mathrm{C}$ with and without $\mathrm{NAD}^{+}$preincubation. (A) Traces were obtained by mixing a solution of T104A-17X-PTDH (200 $\mu \mathrm{M}$ ) with a solution of $10 \mathrm{mM}{ }^{1} \mathrm{H}$ - or ${ }^{2} \mathrm{H}-\mathrm{PT}$ and $10 \mathrm{mM} \mathrm{NAD}^{+}$. (B) Traces were obtained by mixing a solution of T104A-17X-PTDH $(200 \mu \mathrm{M})$ containing $10 \mathrm{mM} \mathrm{NAD}^{+}$with a solution of 10 $\mathrm{mM}{ }^{1} \mathrm{H}$ - or ${ }^{2} \mathrm{H}-\mathrm{PT}$. Data in both panels is fit to the zeroth-order rate law. Insets in both panels contain the first $200 \mathrm{~ms}$ of data. Absorbance values corresponding to a single turnover are 1.24 in both Panels A and B.

Table S3. KIEs obtained with T104X-17X-PTDH by steady-state and pre-steady-state measurements at $5{ }^{\circ} \mathrm{C} .^{\text {a }}$

\begin{tabular}{|c|c|c|c|}
\hline Variant & ${ }^{\mathrm{D}} k_{\text {cat }}{ }^{\mathrm{b}}$ & ${ }^{\mathrm{D}}\left(k_{\text {cat }} / K_{\mathrm{m}, \mathrm{PT}}\right)^{\mathrm{b}}$ & ${ }^{\mathrm{D}} k_{\mathrm{obs}^{\mathrm{c}}}$ \\
\hline T104S & $2.53 \pm 0.06$ & $2.2 \pm 0.2$ & $2.38 \pm 0.04$ \\
\hline T104A & $2.53 \pm 0.02$ & $2.3 \pm 0.2$ & $2.44 \pm 0.02^{\mathrm{d}}$ \\
\hline T104G & $2.44 \pm 0.01$ & $2.3 \pm 0.2$ & $2.44 \pm 0.02^{\mathrm{d}}$ \\
\hline
\end{tabular}

${ }^{\mathrm{a}}$ All data was collected using $100 \mathrm{mM}$ MOPS at $\mathrm{pH} 7.25$. ${ }^{\mathrm{b}}$ Values derived from Michaelis-Menten curves constructed from steady-state measurements obtained using saturating concentrations of $\mathrm{NAD}^{+}$and varied concentration of ${ }^{1} \mathrm{H}$ - or ${ }^{2} \mathrm{H}-\mathrm{PT}$. ${ }^{c}$ Values derived from fits of pre-steady-state traces to the zeroth order rate law. ${ }^{\mathrm{d}}$ Values obtained using data collected in the post-activation phase $(\mathrm{t}>0.2 \mathrm{~s})$.

Table S4. ${ }^{\mathrm{D}} \boldsymbol{k}_{\text {cat }}$ values observed with T104X-17X-PTDH mutants at various temperatures ${ }^{\mathrm{a}}$

\begin{tabular}{|c|c|c|c|}
\hline $\begin{array}{c}\text { Temperature } \\
\left({ }^{\circ} \mathrm{C}\right)\end{array}$ & $\mathrm{T} 104 \mathrm{~S}$ & $\mathrm{~T} 104 \mathrm{~A}$ & $\mathrm{~T} 104 \mathrm{G}$ \\
\hline 5 & $2.53 \pm 0.06$ & $2.53 \pm 0.02$ & $2.44 \pm 0.09$ \\
\hline 15 & $2.37 \pm 0.04$ & $2.39 \pm 0.03$ & $2.30 \pm 0.07$ \\
\hline 25 & $2.27 \pm 0.06$ & $2.3 \pm 0.1$ & $2.19 \pm 0.02$ \\
\hline 35 & $2.20 \pm 0.03$ & $2.17 \pm 0.04$ & $2.10 \pm 0.01$ \\
\hline 45 & $2.16 \pm 0.05$ & $2.03 \pm 0.07$ & $2.05 \pm 0.03$ \\
\hline
\end{tabular}

${ }^{\mathrm{a}} \mathrm{All}$ values obtained in $100 \mathrm{mM}$ MOPS, $\mathrm{pH} 7.25$. Values are the average of three replicates and associated errors are the standard deviation of those replicates. 